\title{
Prenatal Methamphetamine Exposure and Adverse Neonatal Outcomes: A Nationwide Cohort Study
}

\author{
Roman Gabrhelík ${ }^{a, b}$ Svetlana Skurtveit ${ }^{c, d}$ Blanka Nechanskáa ${ }^{a}$ Marte Handal ${ }^{c}$ \\ Milada Mahic c Viktor Mravčík ${ }^{\mathrm{a}, \mathrm{e}}$ \\ aDepartment of Addictology, First Faculty of Medicine, Charles University, Prague, Czech Republic; \\ ${ }^{b}$ Department of Addictology, General University Hospital in Prague, Prague, Czech Republic; 'Norwegian Institute

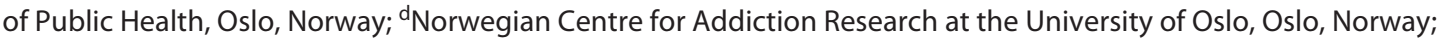 \\ eNational Monitoring Centre for Drugs and Addiction, Office of the Government of the Czech Republic, \\ Prague, Czech Republic
}

\section{Keywords}

Neonatal outcomes · Prenatal exposure .

Methamphetamine $\cdot$ Health registries $\cdot$ Opioids

\begin{abstract}
Background: There is limited knowledge on the adverse outcomes in newborns after maternal methamphetamine (MA) use during pregnancy. Objectives: To compare neonatal outcomes in newborns exposed to MA with the newborns of opioid-exposed mothers and of mothers from the general population (GP). Method: A cohort study using nationwide registries in Czechia (2000-2014). Women hospitalized with a main diagnosis of MA use disorder during pregnancy ( $n=$ 258) and their newborns were defined as MA-exposed. The comparison groups consisted of women $(n=199)$ diagnosed with opioid use disorder during pregnancy, defined as opioid-exposed, and women ( $n=1,511,310)$ with no substance use disorder diagnosis (GP). The neonatal outcomes studied were growth parameters, gestational age, preterm birth, and Apgar score. To explore the associations between MA exposure and neonatal outcomes, regression coefficients $(b)$ and
\end{abstract}

karger@karger.com www.karger.com/ear

Karger $\frac{1}{\%}$

GOPEN ACCESS
(C) 2020 The Author(s)

Published by S. Karger AG, Basel

This article is licensed under the Creative Commons AttributionNonCommercial-NoDerivatives 4.0 International License (CC BYNC-ND) (http://www.karger.com/Services/OpenAccessLicense). Usage and distribution for commercial purposes as well as any distribution of modified material requires written permission. odds ratios from multivariable linear and binary logistic regression were estimated. Results: MA-exposed women had similar socio-economic characteristics to opioid-exposed, both of which were worse than in the GP. After adjustment, MA exposure was associated with a more favourable birthweight when compared to the opioid-exposed (adjusted mean differences [aMD] $b=122.3 \mathrm{~g}, 95 \% \mathrm{Cl}: 26.0-218.5$ ) and length ( $\mathrm{aMD} b=0.6 \mathrm{~cm}, 0.0-1.1$ ). Unadjusted results from the comparison with the GP showed that the MA group had poorer neonatal outcomes, especially in the growth parameters. Adjustment for background characteristics had a profound effect on the comparison with the GP. After adjustment, MA exposure was associated only with a slightly reduced birthweight (aMD $b=-63.0 \mathrm{~g},-123.0$ to -3.1 ) and birth length ( $\mathrm{aMD} b=-0.3 \mathrm{~cm},-0.6$ to 0.0 ). Conclusions: Although the observed negative outcomes were large in the MA-exposed newborns, the adjustment had a profound effect on the comparison with the GP, indicating the large influence of lifestyle and socio-economic factors in these highrisk pregnancies. MA-exposed newborns had better neonatal outcomes compared to opioids-exposed.

(C) 2020 The Author(s)

Published by S. Karger AG, Basel

Roman Gabrhelík

Department of Addictology

First Faculty of Medicine, Charles University

Apolinářská 4, CZ-120 00 Prague 2 (Czechia)

roman.gabrhelik@lf1.cuni.cz 


\section{Introduction}

The use of methamphetamine (MA) hydrochloride is increasing worldwide and represents a serious problem with physical, psychological, and societal damage $[1,2]$. MA has a unique position in the Czech drug scene [3], which is influenced by nearly 50 years' history of use [4] and its high popularity compared to the use of other types of stimulants, such as amphetamine or cocaine, which is of a very low prevalence [5]. The majority of Czech MA users (approximately 80\%) inject the drug [6].

Evidence of the prevalence of MA use during pregnancy is limited. The prevalence of the use may be quite low $(0.1-0.3 \%)$ in countries or regions where MA is not the most preferred drug [7]. In areas where MA use is more widespread, for example Hawaii, MA exposure during pregnancy may extend to $1.4 \%$ [8] but may reach up to $5.2 \%$ in specific populations [9]. Not all women curb their drug use during pregnancy. Della Grotta et al. [10] found that of 191 pregnant women, 55\% did not significantly change the quantity and frequency of their use of MA during the course of their pregnancy, in fact $10 \%$ increased their use, and only one-third decreased their use.

MA-using women are more likely to experience complications during pregnancy [11-14]. In a large retrospective cohort study, which included all pregnancies from 2005 to 2008 in the state of California, Gorman et al. [15] linked MA use during pregnancy to increased risks of preterm birth and mortality compared to the general population (GP). Kalaitzopoulos et al. [16] conducted a meta-analysis of retrospective, case-control studies of 626 women who used MA during pregnancy and 2,626 controls. MA was associated with a shorter gestational age at birth, a lower birthweight, reduced head circumference and body length, and a worse Apgar score when compared with the control pregnancies. In one of the most recent clinical controlled studies, controlling for the most observed confounders, Wright et al. [17] found that MA use during pregnancy $(N=144)$ was associated with a lower birthweight and shorter gestational age. In the Infant Development, Environment, and Lifestyle (IDEAL) study, which was the largest prospective cohort study to date on MA use $(n=204)$ during pregnancy, Nguyen et al. [18] reported an increased risk of "small for gestational age" (SGA) and reduced head circumference and length. Studies to date have not found any neonatal abstinence syndrome requiring pharmacologic intervention in infants exposed to MA in utero [19].

Pregnant women who use drugs differ from the GP of pregnant women with respect to their background char- acteristics such as socio-economic, health, and lifestyle factors [20-26]. Such factors can negatively affect the pregnancy. In this study, we included, in addition to the GP, a comparison group of another drug-using population (opioid users), which we expected to have similar background characteristics to the MA users. Opioid use during pregnancy has previously been shown to be associated with unfavourable background characteristics and a range of neonatal complications such as neonatal abstinence syndrome, spontaneous abortions, intrauterine growth retardation, preterm birth, and a low Apgar score [27-29].

In the Czech Republic, there are nationwide health registries which allow for the linkage of data on individual and family levels [30], and the identification of different populations of pregnant women. We aimed to study the associations between MA use during pregnancy and adverse neonatal outcomes compared to the newborns of opioid-dependent women and newborns of the GP. Specifically, we wanted to investigate if MA exposure resulted in the same level of unfavourable outcomes as for opioids. Furthermore, we wanted to explore the impact of maternal background characteristics on the associations under study.

\section{Methods}

\section{Data Sources}

The National Register of Reproduction Health (NRRH) includes all women have given birth and their children in the Czech Republic. Nearly all births take place in hospitals in the Czech Republic. The NRRH has several sub-registries, including The Mothers at Childbirth Registry and The Registry of Newborns. The first includes information about the mothers during pregnancy and is based on the so-called Pregnancy Card that is compulsory for every pregnant woman to have. The Pregnancy Card contains all relevant information from the pregnancy period such as the demographic and socio-economic information, and information about alcohol, tobacco, and illicit drug use during pregnancy. The information is transferred from the Pregnancy Card to the NRRH at upon birth/stillbirth, together with the additional information collected during the birth. The Registry of Newborns includes information about the neonate, such as growth parameters, congenital malformations, and death.

The National Register of In-patient Treatment (NRIT) includes information about every episode of all types of hospitalizations. The information includes the dates of admission and discharge from hospital as well as the diagnosis on the discharge summary, coded according to the International Statistical Classification of Diseases, 10th Revision (ICD-10).

Physicians are obliged by law to report data to NRRH and NRIT. The linkage of data between the registries is based on the personal identification numbers assigned to all individuals in the Czech Republic [30]. The linkage was performed at the Institute of
98

Eur Addict Res 2021;27:97-106 DOI: $10.1159 / 000509048$
Gabrhelík/Skurtveit/Nechanská/Handal/ Mahic/Mravčík 
Health Information and Statistics of the Czech Republic, which is the owner of the registries. A more detailed description of the registries used is provided elsewhere $[30,31]$.

\section{Study Population and Study Period}

The study population consisted of pregnant women and their newborns born during the study period 2000-2014 in the Czech Republic.

\section{Prenatal Exposure to $M A$}

Pregnant women (registered in the NRRH) who were hospitalized and given a main diagnosis of mental and behavioural disorders due to other stimulant use (ICD-10 code F15, all sub-codes registered in the NRIT) during pregnancy were defined as MAexposed women during pregnancy. The main diagnosis should reflect the main health problem of the patient for the actual hospital stay. Thus, to receive an F15 diagnosis during pregnancy, the woman should have used psychostimulants in pregnancy. Less than $1 \%(n=2)$ of the women in the MA group had an acute intoxication diagnosis. All others had a diagnosis indicating prolonged or heavy use. To reduce the problem of polysubstance use, women hospitalized with 2 or more diagnoses related to different psychoactive substances (F10-F18) or women who were hospitalized for polydrug use (F19) during pregnancy/study period were excluded. In this paper, we refer to women with an ICD-10 F15 diagnosis as "women using MA" since this diagnostic group is nearly exclusively represented by MA in the Czech Republic [32, 33]. The newborns of women using MA during pregnancy are referred to as "MA-exposed." There were no women with $>1$ pregnancy in the MA group.

\section{Comparison Groups}

We used 2 comparison groups:

1. "Opioid-exposed" are defined as women hospitalized with a main diagnosis of mental or behavioural disorder due to opioid use during pregnancy (ICD-10 code F11, all sub-codes). There were no women with $>1$ pregnancy in the opioid-exposed group.

2. "General population" is defined as women who were not diagnosed with any mental or behavioural disorders due to psychoactive substance use (ICD-10 codes F10-F19, all sub-codes) prior to or during pregnancy.

\section{Outcomes}

Neonatal outcomes were identified in the NRRH and included gestational age (mainly based on ultrasound examination, or if missing the first day of the last menstrual period); preterm birth ( $<37$ weeks of gestation); growth parameters (birthweight, length, and head circumference); SGA [34]; caesarean section; stillbirth (death of a foetus in gestational week 22 or later); Apgar scores $<7$ at 1,5 , and $10 \mathrm{~min}$; malformations; treatment in delivery theatre; and treatment in ward.

\section{Other Variables}

Based on what is known from the literature on possible confounders, we obtained available information on sociodemographic variables, illicit drug use, tobacco smoking, alcohol use, the week of the start of prenatal care, and the number of medical controls during prenatal care from the NRRH. Data on alcohol, illicit drug use, and smoking are self-reported, and available from the Preg- nancy Card. The disclosure of illicit drug use should primarily inform the medical staff about the special conditions, and which precautionary measures to take during the birth.

\section{Analysis Strategy and Statistics}

First, we present information on the maternal sociodemographic background, previous abortions, alcohol use, tobacco smoking, and prenatal care during pregnancy. Confidence intervals for proportions were calculated using the continuity-corrected score interval method [35].

Next, we processed neonatal outcomes, restricted to singleton births. Growth parameters (except SGA) were restricted to term births ( $\geq 37$ gestational weeks). Gestational age, SGA, and Apgar scores were restricted to live births.

We performed linear regression for continuous dependent variables and binary logistic regression for categorical dependent variables. To control for relevant background characteristics, we adjusted for maternal age, marital status, education, tobacco smoking, alcohol use during pregnancy, and the number of medical controls during prenatal care, which we also used as a proxy for behaviour influenced by sociocultural factors, such as a drug use-related lifestyle, health literacy, and social support [21]. We compared the MA-exposed children to those from the opioidexposed group and from the GP. We also compared opioid-exposed children to those from the GP. Standard errors were estimated using the clustered sandwich estimator to process multiple pregnancies in the same woman. As some of the neonatal outcomes were infrequent, we only performed a multivariate analysis of outcomes observed in $>4$ individuals. The statistical significance level was set to 0.05 .

We examined the robustness of our findings. We used propensity scores to address imbalances in the baseline confounder distributions between the MA- and opioid-exposed groups, and between the MA-exposed and the GP, separately. The propensity score is the probability of drug use, conditional on the observed baseline characteristics $[36,37]$. The propensity score allows one to analyse an observational study, so that it mimics some of the particular characteristics of a randomized controlled trial. We used the Inverse Probability of Treatment Weighting (IPTW) approaches based on the propensity score to estimate the average effect of MA and assessed the balance of the baseline characteristics in the weighted population using the standardized mean difference, with 0.15 as a cut-off for evidence of imbalance. This resulted in a balanced model when comparing the MA- with opioidexposed, but not when comparing the MA-exposed with the GP. Thus, only the comparison between MA-exposed and opioidexposed was completed and presented in online suppl. Table 1 (www.karger.com/doi/10.1159/000509048). Statistical analyses were conducted using SPSS for Windows, version 21, and Stata 14.

\section{Results}

\section{Background Characteristics}

Women who used MA during pregnancy were quite similar to women who used opioids during pregnancy (Table 1). Among both MA-exposed and opioid-exposed mothers, more than half had only a primary level of edu- 


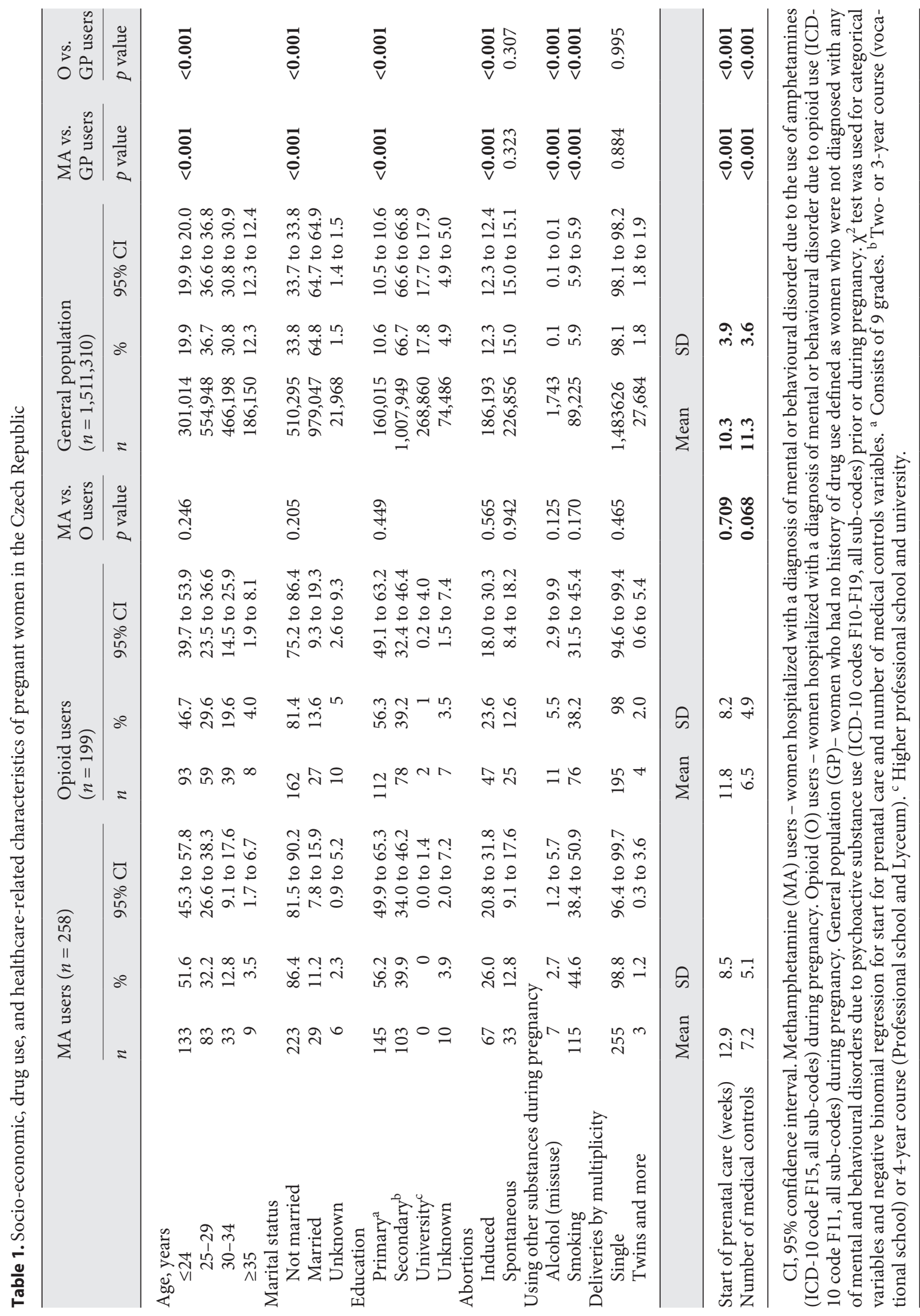


Table 2. Neonatal outcomes in newborns of women using MA or illicit opioids during pregnancy and in the GP in the Czech Republic. Singleton pregnancies

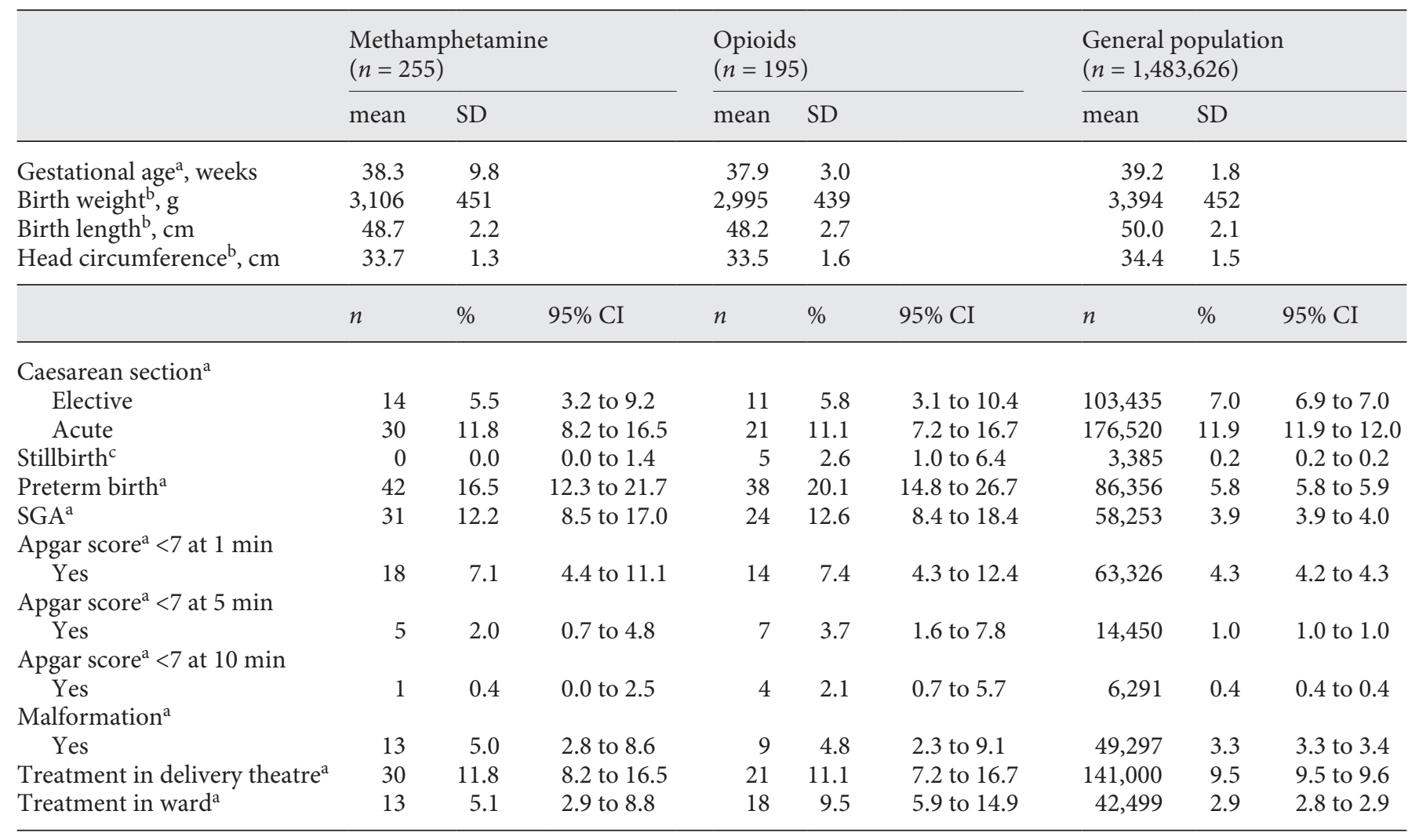

Methamphetamine (MA) - children of women hospitalized with a diagnosis of mental or behavioural disorder due to the use of amphetamines (ICD-10 code F15, all sub-codes) during pregnancy. Opioids - children of women hospitalized with a diagnosis of mental or behavioural disorder due to opioid use (ICD-10 code F11, all sub-codes) during pregnancy. General population (GP) - children of women who had no history of drug use defined as women who were not diagnosed with any of mental and behavioural disorders due to psychoactive substance use (ICD-10 codes F10-F19, all sub-codes) prior or during pregnancy. CI, 95\% confidence interval; SGA, small for gestational age. ${ }^{\mathrm{a}}$ Live births. ${ }^{\mathrm{b}}$ Births with gestational age $\geq 37$ weeks. ${ }^{\mathrm{c}}$ Death of a foetus at gestational week 22 or later.

cation (56.2 and $56.3 \%$, respectively), and a large proportion had previously induced abortions (26.0 and 23.6\%). The smoking prevalence was high in both groups. Both drug-related groups of pregnant women were younger, and a higher proportion were not married and had lower education level compared to the GP of pregnant women. In addition to the socio-economic indicators, $26 \%$ of MA-using women had previously induced abortions, compared to $12.3 \%$ in the GP. MA-using women started their prenatal care 2.5 weeks later and had a substantially lower number (4.1 differences in mean) of medical controls during pregnancy compared to the GP of pregnant women.

\section{Neonatal Outcomes}

In comparison to the opioid-exposed, the newborns in the MA-exposed group had slightly more favourable neonatal outcomes (Table 2). For instance, the mean birthweight was higher, and the proportion of preterm birth was lower in the MA-exposed. The proportion with low Apgar scores after 1, 5, and 10 min decreased more quickly in the MA-exposed newborns compared to the opioidexposed. In both the MA- and opioid-exposed groups, all neonatal outcomes were generally worse than in the GP.

Table 3 first shows the unadjusted and adjusted results of the linear and logistic regression analysis of neonatal outcomes comparing MA-exposed and opioid-exposed newborns with each other and with the GP. The comparison of neonatal outcomes between MA-exposed new- 
Table 3. Linear ${ }^{\mathrm{a}}$ and binary logistic ${ }^{\mathrm{b}}$ regression comparing neonatal outcomes in prenatal MA exposure and illicit opioid exposure and with the general population in the Czech Republic. Singleton pregnancies

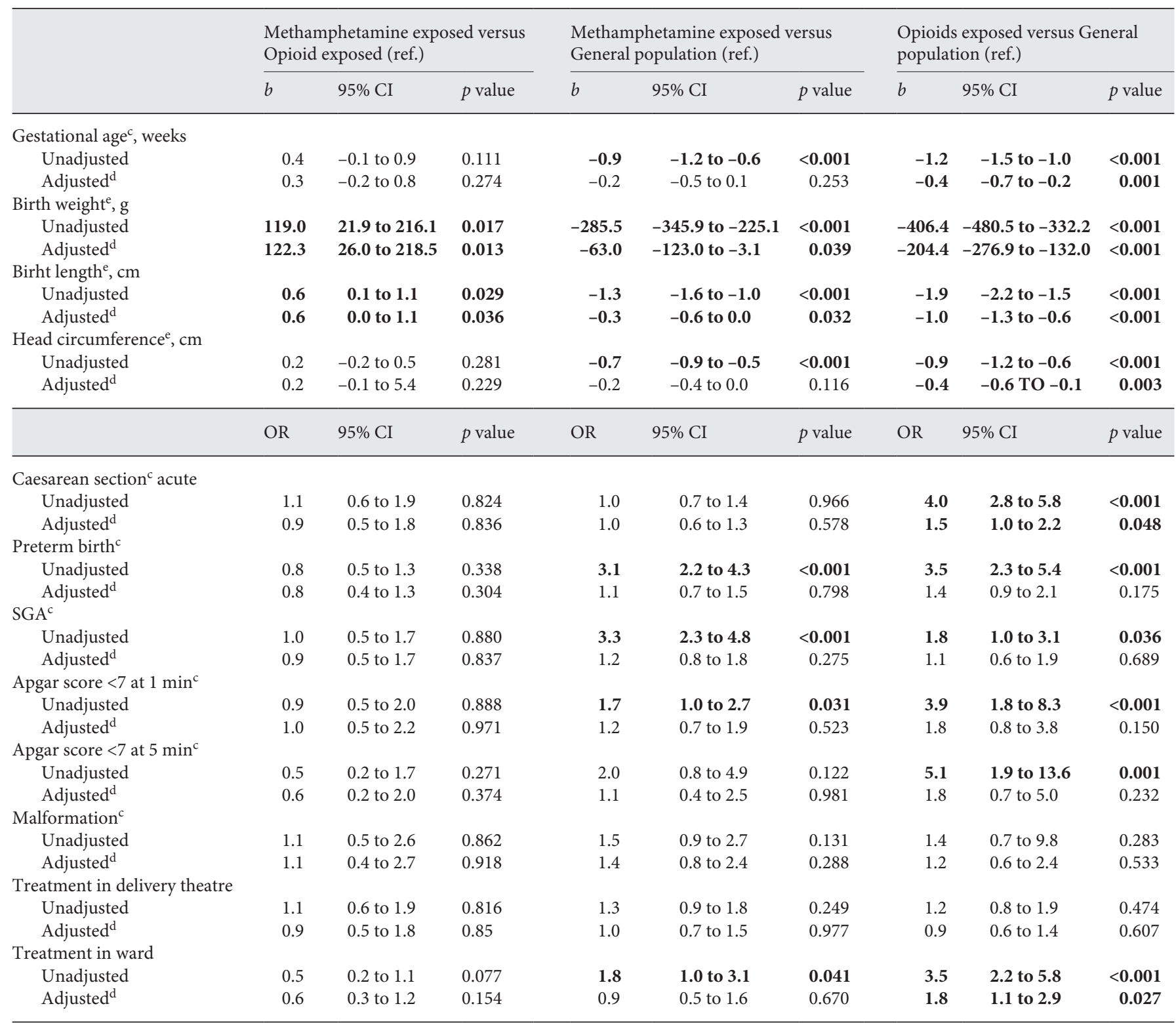

CI, confidence interval; SGA, small for gestational age; OR, odds ratio. Methamphetamine (MA) - children of women hospitalized with a diagnosis of mental or behavioural disorder due to the use of amphetamines (ICD-10 code F15, all sub-codes) during pregnancy. Opioids - children of women hospitalized with a diagnosis of mental or behavioural disorder due to opioid use (ICD-10 code F11, all sub-codes) during pregnancy. General population (GP) children of women who had no history of drug use defined as women who were not diagnosed with any of mental and behavioural disorders due to psychoactive substance use (ICD-10 codes F10-F19, all sub-codes) prior or during pregnancy. ${ }^{\text {a }} b$ (regression coefficients adjusted mean differences) from linear regression for gestational age, birthweight, length, and head circumference. ${ }^{b}$ ORs from binary logistic regression of having childbirth SGA, premature birth, and Apgar score $<7 .{ }^{\mathrm{c}}$ Live births. ${ }^{\mathrm{d}}$ Adjusted for age, marital status, education, smoking, alcohol, and number of medical controls in pregnancy. ${ }^{\mathrm{e}}$ Births with gestational age $\geq 37$ weeks.

borns and opioid-exposed newborns favoured the MAexposed group in nearly all outcomes, but only birthweight and birth length were statistically significant. Adjustment had nearly no impact on the effect estimates for the neonatal outcomes when comparing the MA-exposed and opioid-exposed groups. For instance, the birthweight was around $120 \mathrm{~g}$ higher and birth length 0.6 $\mathrm{cm}$ longer in the MA-exposed group both in the unad- 
justed and adjusted analyses. The favourable results of MA exposure compared to opioid exposure on growth parameters stayed consistent in the additional analyses using the IPTW method (online suppl. Table 1).

When the MA-exposed were compared to the GP, the unadjusted results showed profound negative outcomes, for instance, shorter gestational age ( -0.9 week), lower birthweight ( $-285 \mathrm{~g})$, and increased risk of SGA (odds ratio $[\mathrm{OR}]=3.3)$ and preterm birth $(\mathrm{OR}=3.1)($ Table 3$)$. The differences were even worse for the opioid-exposed newborns. The adjustment had a profound impact on the risk estimates of adverse neonatal outcomes in MA-exposed newborns when compared to the GP (Table 3). After adjustment, only birthweight and birth length remained statistically significantly smaller. The adjusted mean difference in birthweight was $-63.0 \mathrm{~g}$ (95\% CI: -123.0 to -3.1$)$ and in birth length was $-0.3 \mathrm{~cm}(-0.6$ to $0.0)$. A reduction in all estimates was observed between the opioid-exposed group and the GP after adjustment, while gestational age, birthweight and birth length, head circumference, and delivery via caesarean section remained statistically significantly worse in newborns exposed to opioids during pregnancy (Table 3 ).

\section{Discussion}

In this observational cohort study using nationwide register data, we investigated the neonatal outcomes of children prenatally exposed to MA and opioids and children from the GP. When the MA- and opioid-exposed newborns were compared, birthweight and birth length were higher in the MA-exposed. We found profound differences in the neonatal outcomes when the MA-exposed were compared to the GP, but after adjustment for socio-economic and lifestyle parameters, the differences remained statistically significant only for birthweight $(-63 \mathrm{~g})$ and birth length $(-0.3 \mathrm{~cm})$. The adjustment had nearly no effect when we compared the 2 drug-using populations, which had similar background characteristics, whereas it had a profound effect when comparing the MA-exposed and opioid-exposed to the GP, which had very different background characteristic distributions.

Previous research has observed a lower birthweight in children exposed to MA during their foetal life when compared to the non-exposed [17-19]. In some of the studies, the difference disappeared after adjustment [18], while in others, there was still a difference in birthweight $[17,19]$. In our study, the adjustment profoundly reduced

Methamphetamine and Adverse Neonatal Outcomes the clinical relevance of the difference in birthweight when compared to GP to a questionable level.

Other studies have also reported an increased risk of SGA, decreased head circumference, and lower Apgar score in the MA-exposed newborns, compared to the GP [16]. Our results did not support such findings. Furthermore, no stillbirths were reported among the MA-exposed women in our study, which is in contrast to Gorman et al. [15] who found a high risk of intrauterine death (adjusted $\mathrm{OR}=5.1,95 \% \mathrm{CI}: 3.7-7.2)$. However, despite the fact that our study population of the MA-exposed was smaller, all together the prevalence of stillbirth was very low in the GP. This might indicate that a nationwide lower prevalence of stillbirths also affects the prevalence in the subpopulations under study. Furthermore, in line with Gorman et al. [15], we found an increased risk of preterm birth in the MA group in the unadjusted analysis, but this association diminished in the adjusted model. It is obvious that comparisons with other studies may be affected by differences in both the MA dose and the route of administration in the populations studied. No such information was available in the registries. Perhaps, our population of MA-exposed women used lower doses, had shorter duration of use, or were not exposed to MA in the most sensitive periods of pregnancy. Regarding the route of administration, the majority of Czech users use MA intravenously, and so could women in our MA group. Not only is intravenous use considered the riskiest route of administration [38,39], more severe MA dependence is associated with injecting MA rather than with ingesting [40], smoking, or intranasal use [40,41]. Conceivably, the MAexposed women in our study may have transitioned from intravenous use to less harmful routes of administration.

When we compared the MA-exposed newborns to the opioid-exposed newborns, we observed a higher birthweight and birth length among the MA-exposed. Thus, opioid exposure seems to be associated with more harmful effects on neonatal outcomes than MA exposure, and we can only speculate on the reasons for this. Opioids and MA have different mechanisms of action that might affect foetal development differently or the mechanism might be more indirect. For example, opioid use might affect maternal respiratory rate and blood pressure differently from MA, and the opioid-induced physiological changes might affect the foetus negatively. A third possibility might be that opioid drug use patterns have a greater impact on the women's lifestyle than MA use. We used the number of medical controls during pregnancy care as a measure of a chaotic lifestyle and thus as a proxy for some unmeasured confounders. 
The results of this study showed the importance of the choice of comparison group and adjustment. Adjustment for measured confounders seems to be crucial when studying the effects of prenatal MA exposure. Several previously mentioned studies have adjusted for important confounding factors and still found associations with adverse outcomes. Most of the published studies compared MAexposed newborns with the GP. Only Wright et al. [17] compared MA exposed pregnancies with non-MA exposed pregnancies, consisting of women who either had a history of MA use prior to pregnancy, used only tobacco, used drugs other than MA, or had no record of illicit drug use but obtained care from the treatment facility and thus were from the same catchment area and of similar socioeconomic status. The GP differs in terms of important characteristics such as lifestyle, sociodemographic characteristics, access to and quality of healthcare, and drug use history. In the current study, when comparing the MAexposed to the GP, adjustment for the measured sociodemographic and lifestyle confounders had a strong effect on the estimate. A similar pattern was observed after comparison of opioid-exposed newborns with the GP. On the contrary, when we included a comparison group of opioid users, which was expected to have similar distributions of measured and unmeasured confounders to the MA-exposed, we did not observe any effect of the adjustment.

Our findings, represented by the reduction in most of the measures after adjustment, might suggest that the underlying risk for adverse neonatal outcomes may be linked to a complex of sociocultural factors including the lifestyle associated with drug use, poorer health literacy, the time needed to accept one's own pregnancy, and addressing other priorities in life before seeking antenatal care $[20,42]$. In non-using populations, the evidence suggests that the complex background characteristics contribute to worsened birth outcomes. Socio-economic status was found to negatively affect pregnancy outcomes, namely higher rates of abortion, caesarean delivery, preeclampsia, preterm delivery, and obstetrical haemorrhage [20]. Based on a large US cross-sectional study, women from areas with higher population well-being had a lower risk of preterm birth, even after accounting for individual risk factors [43]. Neighbourhood poverty, nutrition factors, and social and environmental exposures influence birthweight and the risk of preterm birth [44-46]. Multiple aspects of deprivation and poor social support are key risk factors that influence the timing of maternal engagement with antenatal care [21]. In substance using populations, drug use prior to or even during pregnancy further contributes to a higher risk of deprivation indicators and poor social support [10]. Schempf and Strobino [47] attributed $70 \%$ of adverse neonatal outcomes to the surrounding psychosocial and behavioural factors in cocaine-exposed women, particularly smoking and stress, while most of the adverse neonatal outcomes were attributed to smoking and a lack of early prenatal care in opioid-exposed women. Worsened socio-economic situation, poorer pregnancy care, and a higher risk of foetal growth restriction (as indicated by SGA) were associated with substance use disorders (illicit and licit, including alcohol and sedatives/hypnotics) diagnosed during pregnancy, when compared to women without a substance use disorder [48]. A greater number of prenatal care visits were found to be linked with the decreased use of MA over the course of the pregnancy [10]. Therefore, the importance of controlling for prenatal care [49] and other lifestyle-related factors should be considered when conducting future risk estimates.

\section{Methodological Considerations}

The strength of the current study was the size of the sample of women using MA during pregnancy. In addition, the use of national health registries reduces both selection bias and the risk of recall bias that is often present in studies using self-reported data.

One limitation is the definition of the exposure. By our definition, we did not identify all pregnant women using substances during pregnancy, only those requiring hospitalization caused by such use. By defining exposure as a diagnosis of substance use disorder during pregnancy, we possibly identified the heaviest users. Even though our definition results in misclassification, Greenland [50] has pointed out that when the prevalence of exposure is low, specificity, rather than sensitivity, has a greater effect on the underestimation of risk. Therefore, it is most important to minimize the number of truly unexposed patients in the exposed group, as we have intended to do by using our definition of MA use.

The registries include less information about potential confounding factors than clinical studies (e.g., information on nutrition, infections during pregnancy, and a woman's body mass index). Some important information may be underreported or reported in an insufficient format in the registries (e.g., use of alcohol, tobacco, and illicit drugs), or information may be missing. This may be especially true in the comparison with the GP, where the confounder distributions between the compared groups were different, residual confounding might still exist, and the already small difference in growth parameters could in fact be even smaller. 
We used 2 different methods for the adjustment for confounders in this study: traditional adjustment by multivariable regression and the IPTW method. When comparing the MA-exposed to the GP, we did not achieve a balanced model, and therefore, causal inference is not possible to accomplish with regard to the effects of MA exposure.

Furthermore, despite MA being reported in the registries as the primary problematic drug, users may have combined MA with the unregistered use of other drugs. Additionally, we had no information about the dose, timing, and duration of use, nor of any discontinuation of use during pregnancy. Discontinuation of the use of MA at any time during pregnancy may improve birth outcomes [17].

Finally, as there was no reference population available for SGA in the Czech Republic, we used the Swedish reference population in our calculations [34]. This may have resulted in incorrect population estimates of SGA, but the relative differences between the groups should not be affected.

\section{Conclusion}

Newborns who were prenatally exposed to MA had profound negative neonatal outcomes. This study shows that these clinically observed adverse neonatal outcomes may, to a large extent, be attributed to a drug-related lifestyle and socio-economic risk factors. These findings can inform clinicians about the importance of broadening the focus from MA use and to include the other factors linked to MA use among pregnant women.

\section{Conflict of Interest Statement}

There are no conflicts of interest.

\section{Funding Sources}

The study was supported by the Ministry of Health of the Czech Republic, Grant No. 16-28157A, and from the Norwegian Research Council, Grant No. 240197/H10.

\section{Author Contributions}

B.N. had full access to all of the data in the study and takes responsibility for the integrity of the data and the accuracy of the data analysis. Concept and design: R.G., S.S., M.H., and V.M. Acquisition, analysis, or interpretation of data: R.G., B.N., S.S., M.H., and M.M. Drafting of the manuscript: R.G., S.S., and M.H. Critical revision of the manuscript for important intellectual content: R.G., S.S., M.H., V.M., and M.M. Statistical analysis: B.N. and S.S. Obtained funding: R.G., B.N., V.M., S.S., M.H., and M.M. Administrative, technical, or material support: R.G. Supervision: V.M. and M.H.

\section{References}

1 Mounteney J, Groshkova T, Thanki D, Cunningham A, Rychert M, European Monitoring Centre for Drugs and Drug Addiction. Exploring methamphetamine trends in Europe. [Internet]. Luxembourg: Publications Office; 2014 [cited 2019 Mar 9]. Available from: http: //dx.publications.europa.eu/10.2810/24048

2 Vereinte Nationen. Büro für Drogenkontrolle und Verbrechensbekämpfung. World drug report 2018. Vienna: United Nations; 2018.

3 Griffiths P, Mravcik V, Lopez D, Klempova D. Quite a lot of smoke but very limited fire: the use of methamphetamine in Europe. Drug Alcohol Rev. 2008;27:236-42.

4 Brenza J, Gabrhelík R. Use of opioid and stimulant medications in the Czech Socialist Republic before the "discovery" of the clandestine manufacturing of locally-specific stimulants and opiates. Adiktologie. 2014; 14: 284-93.

5 Mravčík V, Chomynová $\mathrm{P}$, Grohmannová K, Nečas V, Grolmusová L, Kiššová L, et al. Výroční zpráva o stavu ve věcech drog v České republice v roce 2016. Prague: Úřad vlády České republiky; 2017.
6 Mravčík V, Chomynová P, Grohmannová K, Janíková $\mathrm{B}$, Tion Leštinová $\mathrm{Z}$, Rous $\mathrm{U}$, et al. Annual report on drug situation 2013: Czech Republic. Prague: Úřad vlády České republiky; 2014.

7 Abdel-Latif ME, Oei J, Craig F, Lui K; NSW and ACT NAS Epidemiology Group. Profile of infants born to drug-using mothers: a state-wide audit. J Paediatr Child Health. 2013;49:E80-6.

8 Derauf C, Katz AR, Frank DA, Grandinetti A, Easa D. The prevalence of methamphetamine and other drug use during pregnancy in $\mathrm{Ha}$ waii. J Drug Issues. 2003;33:1001-16.

9 Arria AM, Derauf C, La Gasse LL, Grant P, Shah $\mathrm{R}$, Smith L, et al. Methamphetamine and other substance use during pregnancy: preliminary estimates from the Infant Development, Environment, and Lifestyle (IDEAL) study. Matern Child Health J. 2006;10:293-302.

10 Della Grotta S, LaGasse LL, Arria AM, Derauf C, Grant P, Smith LM, et al. Patterns of methamphetamine use during pregnancy: results from the Infant Development, Environment, and Lifestyle (IDEAL) study. Matern Child Health J. 2010;14:519-27.
11 Eriksson M, Larsson G, Zetterström R. Amphetamine addiction and pregnancy: II. Pregnancy, delivery and the neonatal period. Socio-medical aspects. Acta Obstet Gynecol Scand. 1981;60:253-9.

12 Little BB, Snell LM, Gilstrap LC. Methamphetamine abuse during pregnancy: outcome and fetal effects. Obstet Gynecol. 1988;72: 541-4.

13 Albertson TE, Derlet RW, Van Hoozen BE. Methamphetamine and the expanding complications of amphetamines. West J Med. 1999;170:214-9.

14 Cox S, Posner SF, Kourtis AP, Jamieson DJ. Hospitalizations with amphetamine abuse among pregnant women. Obstet Gynecol. 2008;111:341-7.

15 Gorman MC, Orme KS, Nguyen NT, Kent EJ, Caughey AB. Outcomes in pregnancies complicated by methamphetamine use. Am J Obstet Gynecol. 2014;211:429.e1-7.

16 Kalaitzopoulos D-R, Chatzistergiou K, Amylidi A-L, Kokkinidis DG, Goulis DG, et al. Effect of methamphetamine hydrochloride on pregnancy outcome. J Addict Med. 2018;12:220-6. 
17 Wright TE, Schuetter R, Tellei J, Sauvage L. Methamphetamines and pregnancy outcomes. J Addict Med. 2015;9:111-7.

18 Nguyen D, Smith LM, Lagasse LL, Derauf C, Grant $P$, Sha R, et al. Intrauterine growth of infants exposed to prenatal methamphetamine: results from the infant development, environment, and lifestyle study. J Pediatr. 2010;157:337-9.

19 Smith LM, Diaz S, LaGasse LL, Wouldes T, Derauf C, Newman E, et al. Developmental and behavioral consequences of prenatal methamphetamine exposure: a review of the Infant Development, Environment, and Lifestyle (IDEAL) study. Neurotoxicol Teratol. 2015;51:35-44.

20 Kim MK, Lee SM, Bae S-H, Kim HJ, Lim NG, Yoon S-J, et al. Socioeconomic status can affect pregnancy outcomes and complications, even with a universal healthcare system. Int $J$ Equity Health. 2018;17:2.

21 Kapaya H, Mercer E, Boffey F, Jones G, Mitchell C, Anumba D, et al. Deprivation and poor psychosocial support are key determinants of late antenatal presentation and poor fetal outcomes-a combined retrospective and prospective study. BMC Pregnancy Childbirth. 2015;15:309.

22 Leppälahti S, Gissler M, Mentula M, Heikinheimo $\mathrm{O}$. Is teenage pregnancy an obstetric risk in a welfare society? A population-based study in Finland, from 2006 to 2011. BMJ Open. 2013;3:e003225.

23 Feijen-de Jong EI, Jansen DE, Baarveld F, van der Schans CP, Schellevis FG, Reijneveld SA. Determinants of late and/or inadequate use of prenatal healthcare in high-income countries: a systematic review. Eur J Public Health. 2012; 22:904-13.

24 Funkhouser AW, Butz AM, Feng TI, McCaul ME, Rosenstein BJ. Prenatal care and drug use in pregnant women. Drug Alcohol Depend. 1993;33:1-9.

25 Forray A. Substance use during pregnancy. F1000Research. 2016;5:887.

26 Skurtveit S, Nechanská B, Handal M, Mravčík V, Gabrhelík R. Hospitalization of children after prenatal exposure to opioid maintenance therapy during pregnancy: a national registry study from the Czech Republic. Addiction. 2019;114:1225-35.

27 Kaltenbach K, Berghella V, Finnegan L. Opioid dependence during pregnancy. Effects and management. Obstet Gynecol Clin North Am. 1998;25:139-51.
28 Wachman EM, Schiff DM, Silverstein M. Neonatal abstinence syndrome: advances in diagnosis and treatment. JAMA. 2018;319: 1362.

29 Handal M, Nechanská B, Skurtveit S, Gabrhelík R, Engeland A, Mravčík V. Prenatal exposure to opioid maintenance treatment and neonatal outcomes: nationwide registry studies from the Czech Republic and Norway. Pharmacol Res Perspect. 2019;7:e00501.

30 Gabrhelík R, Nechanská B, Mravčík V, Skurtveit S, Lund IO, Handal M. A unique opportunity to study short- and long-term consequences in children prenatally exposed to illicit drugs and opioid maintenance treatment using Czech and Scandinavian registers. Cent Eur J Public Health. 2016;24:248-51.

31 Nechanská B, Mravčík V, Skurtveit S, Lund IO, Gabrhelík R, Engeland G, et al. Neonatal outcomes after fetal exposure to methadone and buprenorphine: national registry studies from the Czech Republic and Norway. Addiction. 2018;113:1286-94.

32 Minařík J, Gabrhelík R, Malcolm R, Pavlovská A, Miller P. Methylphenidate substitution for methamphetamine addiction and implications for future randomized clinical trials: a unique case series. J Subst Use. 2016;21:4358.

33 European Monitoring Centre for Drugs and Drug Addiction. European drug report 2019: trends and developments. 2019 [cited 2019 Aug 17]. Available from: https://data.europa. eu/doi/10.2810/191370.

34 Maršál K, Persson P-H, Larsen T, Lilja H, Selbing A, Sultan B. Intrauterine growth curves based on ultrasonically estimated foetal weights. Acta Paediatr. 1996;85:843-8.

35 Vollset SE. Confidence intervals for a binomial proportion. Stat Med. 1993;12:809-24.

36 Rosenbaum PR, Rubin DB. The central role of the propensity score in observational studies for causal effects. Biometrika. 1983;70:41-55.

37 Austin PC. An introduction to propensity score methods for reducing the effects of confounding in observational studies. Multivar Behav Res. 2011;46:399-424.

38 Wiessing L, Ferri M, Grady B, Kantzanou M, Sperle I, Cullen KJ, et al. Hepatitis C virus infection epidemiology among people who inject drugs in Europe: a systematic review of data for scaling up treatment and prevention. PLoS One. 2014; 9:e103345.

39 Darke S. Mortality amongst illicit drug users: epidemiology, causes and intervention. Cambridge: Cambridge University Press; 2012.
40 Mravčík V, Škařupová K, Orlíková B, Zábranský T, Karachaliou K, Schulte B. Use of gelatine capsules for application of methamphetamine: a new harm reduction approach. Int $J$ Drug Policy. 2011;22:172-3.

41 McKetin R, Ross J, Kelly E, Baker A, Lee N, Lubman DI, et al. Characteristics and harms associated with injecting versus smoking methamphetamine among methamphetamine treatment entrants. Drug Alcohol Rev. 2008;27:277-85.

42 Hatherall B, Morris J, Jamal F, Sweeney L, Wiggins M, Kaur I, et al. Timing of the initiation of antenatal care: an exploratory qualitative study of women and service providers in East London. Midwifery. 2016;36:1-7.

43 Riley C, Roy B, Herrin J, Spatz E, Silvestri MT, Arora A, et al. Do pregnant women living in higher well-being populations in the USA experience lower risk of preterm delivery? A cross-sectional study. BMJ Open. 2019;9: e024143.

44 Ncube CN, Enquobahrie DA, Albert SM, Herrick AL, Burke JG. Association of neighborhood context with offspring risk of preterm birth and low birthweight: a systematic review and meta-analysis of populationbased studies. Soc Sci Med. 2016;153:156-64.

45 Ma X, Liu J, Hardin JW, Zhao G, Liese AD. Neighborhood food access and birth outcomes in South Carolina. Matern Child Health J. 2016;20:187-95.

46 Burris HH, Baccarelli AA, Wright RO, Wright RJ. Epigenetics: linking social and environmental exposures to preterm birth. Pediatr Res. 2016;79:136-40.

47 Schempf AH, Strobino DM. Illicit drug use and adverse birth outcomes: is it drugs or context? J Urban Health. 2008;85:858-73.

48 Mravčík V, Nechanská B, Gabrhelík R, Handal M, Mahic M, Skurtveit S. Socioeconomic characteristics of women with substance use disorder during pregnancy and neonatal outcomes in their newborns: a national registry study from the Czech Republic. Drug Alcohol Depend. 2020;209:107933.

49 Haddrill R, Jones GL, Mitchell CA, Anumba DO. Understanding delayed access to antenatal care: a qualitative interview study. BMC Pregnancy Childbirth.2014;14:207.

50 Greenland S.. The effect of misclassification in the presence of covariates. Am J Epidemiol. 1980;112:564-9. 